Fabrication of nano-sized grains by pulsed laser surface melting

This article has been downloaded from IOPscience. Please scroll down to see the full text article.

2010 J. Phys. D: Appl. Phys. 43095402

(http://iopscience.iop.org/0022-3727/43/9/095402)

View the table of contents for this issue, or go to the journal homepage for more

Download details:

IP Address: 159.226.231.70

The article was downloaded on 29/03/2011 at 01:46

Please note that terms and conditions apply. 


\title{
Fabrication of nano-sized grains by pulsed laser surface melting
}

\author{
Chengtao Wang ${ }^{1,2}$, Hong Zhou ${ }^{1,7}$, Pengyu $\operatorname{lin}^{1}$, Na Sun ${ }^{1}$, Qingchen Guo ${ }^{3}$, \\ Jiaxiang Yu ${ }^{1}$, Mingxing Wang ${ }^{4}$, Yu Zhao ${ }^{5}$ and Luquan Ren ${ }^{6}$ \\ ${ }^{1}$ Key Lab of Automobile Materials, Ministry of Education, Jilin University, Changchun 130025, \\ People's Republic of China \\ ${ }^{2}$ Faw-Volkswagen Automotive Company Ltd, Changchun 130011, People's Republic of China \\ ${ }^{3}$ Brilliance Automobile Engineering Research Institute, Shenyang 110141, People's Republic of China \\ ${ }^{4}$ State Key Laboratory of Nonlinear Mechanics, Institute of Mechanics, Chinese Academy of Sciences, \\ Beijing 100190, People's Republic of China \\ ${ }^{5}$ School of Materials Science and Engineering, Changchun University of Technology, Changchun \\ 130012, People's Republic of China \\ ${ }^{6}$ Key Lab of Terrain Machinery Bionics Engineering, Ministry of Education, Jilin University, \\ Changchun 130025, People's Republic of China
}

E-mail: wangct08@mails.jlu.edu.cn

Received 29 November 2009, in final form 14 January 2010

Published 19 February 2010

Online at stacks.iop.org/JPhysD/43/095402

\begin{abstract}
In this work, the formation and characterization of nano-sized grains on the modified surfaces of GCr15 and H13 steels have been investigated. The material was processed by pulsed laser surface melting (LSM) under different depths of de-ionized water. The microstructures and phases of the melted zones were examined by x-ray diffraction, environmental field emission scanning electron microscopy and high resolution transmission electron microscopy. The results indicate that LSM under water can successfully fabricate nano-scaled grains on the surfaces of steel, due to the rapid solidification and crystallization by heterogeneous nucleation. The elemental segregation of chromium and activated heterogeneous nucleation mechanism of austenite in liquid metal play a key role in the formation of nano-sized grains at high cooling rates. This one-step technique provides us a new way to prepare uniform nano-scaled grains, and is of great importance for further understanding the growth of nano-materials under extreme conditions.
\end{abstract}

\section{Introduction}

Laser surface melting (LSM) has been investigated for improving the surface properties of components, since the modified microstructures processed by laser can significantly increase the hardness, corrosion and wear resistance of materials [1]. Previous work on surface melting and quenching of $\mathrm{Fe}-\mathrm{C}$ alloys shows rapidly solidified structures with ultrafine grains or eutectics [2]. The eutectic dendrites with ultrafine secondary arm or lamellar spacing lead to an improvement in physicochemical and mechanical properties such as corrosion [3], cavitation erosion [4], wear [5], fatigue resistance and fracture toughness [6].

\footnotetext{
7 Author to whom any correspondence should be addressed.
}

Many researchers have been focused on improving the surface properties of steel and cast iron as they are the most widely used materials in industry [7-10]. McDaniels et al investigated the role of laser generated heat-affected zone (HAZ) on the fatigue life of AISI 4340 steel, and found that the HAZ did not appear to have an adverse influence on the high-cycle fatigue behaviour [11]. LSM aims at the refinement of the surface microstructure by melting and has been successfully applied on steel to improve the wear resistance properties [12-18]. Kwok et al [19] studied the pitting corrosion behavior of laser surface-melted specimens processed under different processing conditions in $3.5 \% \mathrm{NaCl}$ solution at $23^{\circ} \mathrm{C}$ by the potentiodynamic polarization technique. They found that the pitting corrosion 
Table 1. Chemical compositions of materials used in the experiments (wt\%).

\begin{tabular}{llllllllllr}
\hline & \multicolumn{10}{c}{ Elements } \\
\cline { 2 - 11 } Material & C & Si & Mn & Cr & V & Mo & Re & Mg & P & \multicolumn{1}{c}{ S } \\
\hline CGI & 3.560 & 2.560 & 0.710 & - & - & - & 0.020 & 0.020 & 0.030 & 0.030 \\
GCr15 & 0.950 & 0.200 & 0.300 & 1.350 & - & - & - & - & $<0.027$ & $<0.020$ \\
H13 & 0.360 & 1.090 & 0.320 & 5.120 & 0.480 & 1.320 & - & - & 0.023 & 0.025 \\
\hline
\end{tabular}

characteristics of the laser surface-melted specimens were strongly dependent on the processing condition which resulted in different microstructures. Conde et al [20] investigated the corrosion behaviour of three types of stainless steels (austenitic, martensitic and ferritic) and found that, after LSM, most of the steels presented a shift in pitting potential to more noble values, a longer passivity stage and lower passive current density. It was confirmed that the corrosion resistance was improved by LSM and depended on the laser processing parameters, particularly for the cases of ferritic and martensitic stainless steels. The effect has been mainly attributed to grain refinement and phase transition. The benefits of grain refinement on metals have been well known for a long time. And nano-materials are experiencing a rapid development in recent years due to their existing and potential applications in a wide variety of technological areas such as electronics, catalysis, ceramics, magnetic data storage and structural components. There is much work focusing on related fields. Cui et al [21] have developed an approach to fabricate sharp and high aspect ratio metal tips using nanosecond pulse laser melting. It is found that the molten $\mathrm{Cr}$ films could self-form discrete metal pillars connecting two wafers and also, the selfformation of $\mathrm{Cr}$ pillars was observed. The connection between the two wafers was attributed to the attractive electrostatic force caused by the work function difference of two wafers that were in close proximity. Xia and Chou [22] proposed and demonstrated a new method for fabricating periodic arrays of metal nano-dots over a large area through pulsed laser melting induced fragmentation of metal nano-gratings. They found that the laser melting broke the metal nano-gratings into periodic nano-dots and concluded the control of the nano-dot array pitch using a substrate surface topology. The benefits of grain refinement on metals have been well known for a long time. Nano-crystalline materials with grain sizes in the nanometre range are also known to exhibit superior hardness and strength [23-25]. Indeed, many processing routes have been developed for the synthesis and commercial production of nano-materials including vapour, liquid and solid state processing routes and combined method, such as vapoursolid-liquid approach. However, few reports about the nanocrystalline grains in metals have been achieved under Nd: YAG pulsed LSM.

In this study, pulsed LSM technique was employed to process GCr15 and H13 steels and compacted graphite cast iron specimens. Unlike some methods for nano-materials fabrication, the current one is capable of producing uniform grains at the nanometre scale at ambient conditions, without extreme temperature or pressure.

\section{Experimental details}

\subsection{Materials}

Compact graphite cast iron (CGI), bearing steel (GCr15) and die steel (H13) were used in this study. Their chemical compositions are listed in table 1.

\subsection{Preparation of metal nano-crystalline grains}

Specimens were machined into a size of $14 \mathrm{~mm} \times 10 \mathrm{~mm} \times$ $10 \mathrm{~mm}$ and polished to a surface roughness of $0.04 \mu \mathrm{m}$. Figure 1 is a schematic of the setup used for the underwater LSM process. A quartz glass vessel was used for containing different amount of de-ionized water, which was continuously stirred. Specimens were immersed into water with a selected thickness of water film, i.e. 1,2 and $3 \mathrm{~mm}$. An Nd: YAG pulsed laser with a wavelength of $1064 \mathrm{~nm}$ was chosen for processing the underwater specimens, using the parameters of frequency $3 \mathrm{~Hz}$, pulse duration $5 \mathrm{~ms}$, energy input fluence $160 \mathrm{~J} \mathrm{~cm}^{-2}$, defocusing amount $5 \mathrm{~mm}$ and a circular spot size $2 \mathrm{~mm}$ in diameter on the specimen surface. Assist gas was not used in our experiment. Afterwards, the specimens were ultrasonically cleaned with ethanol to remove surface sediments.

\subsection{Characterization techniques}

After laser melting, the melted surfaces were polished with waterproof abrasive papers and diamond slurry, and then etched in a $4 \%$ nital solution. Confocal scanning laser microscopy (CSLM, LEXT OLS 3000), environmental field emission scanning electron microscopy (EFESEM), $\mathrm{X}$-ray diffraction (XRD) and high resolution transmission electron microscopy (HRTEM, JEM-2100F) were used for microstructural analysis. An ultrathin windowed energydispersive x-ray spectrometer (EDX) and a Gatan imaging filter (GIF) attached to the TEM were used to determine the chemical composition of the nano-sized grains. Thin foil samples for TEM observation were prepared first by polishing mechanically to remove unmelted substrate under $70 \mu \mathrm{m}$, then twin-jet electropolishing using a 10\% perchloric acid in ethanol mixture at $0{ }^{\circ} \mathrm{C}$ and $35 \mathrm{~V}$ and thinned to less than $30 \mu \mathrm{m}$ by an ion beam thinner. 


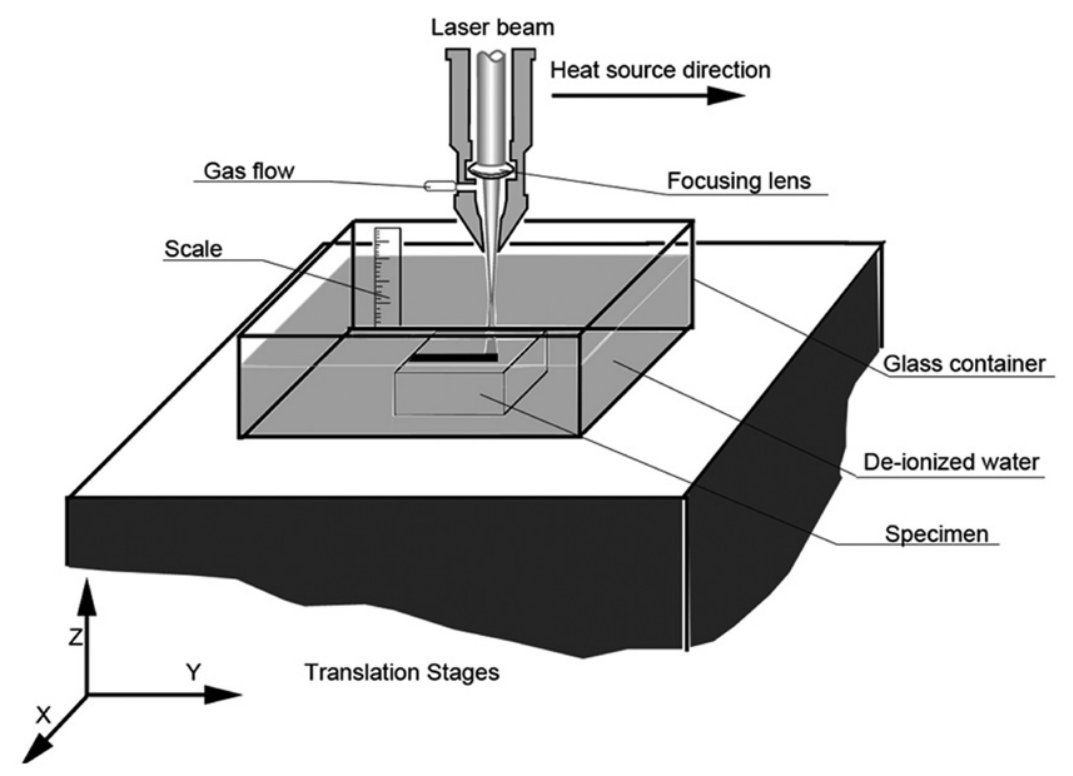

Figure 1. Schematic of the setup used for LSM of metal specimens in water.
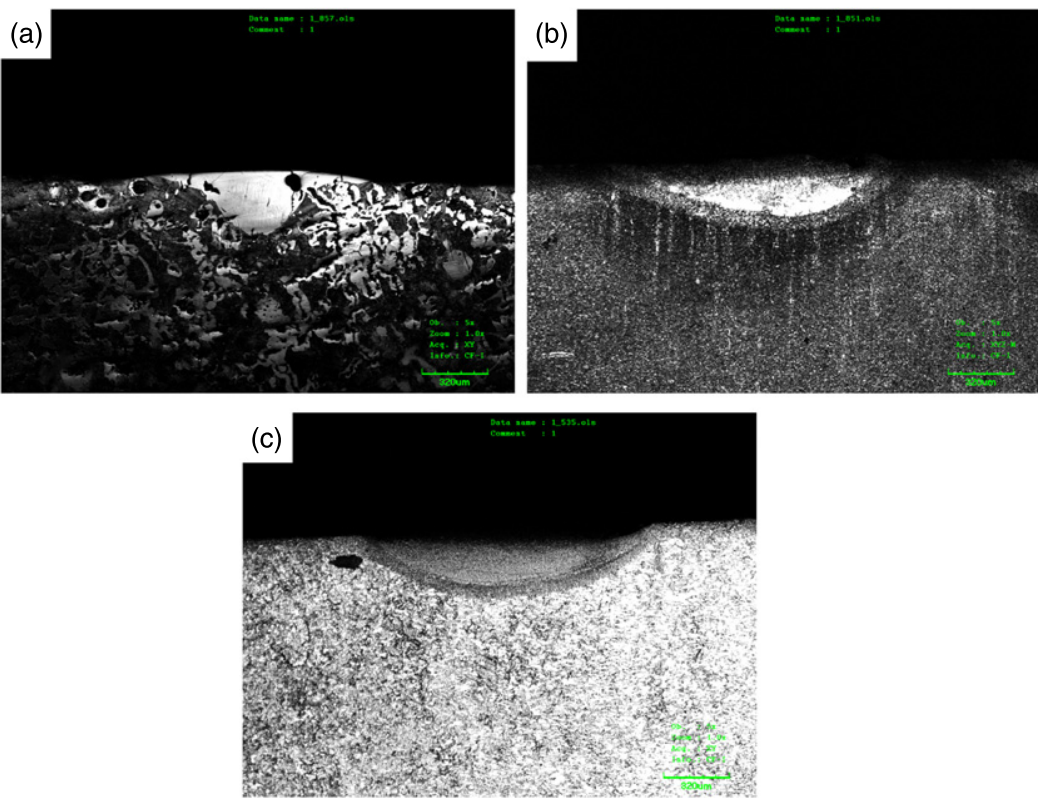

Figure 2. Cross sections of the melted morphology by laser in water in thickness of 3 mm: (a) CGI, (b) GCR15 and (c) H13.

(This figure is in colour only in the electronic version)

\section{Results and discussions}

\subsection{Microstructures of different metal specimens melted under water}

3.1.1. Morphology and structure characterization: CSLM and SEM. Figure 2 shows the microstructures of three different materials processed by laser under $1 \mathrm{~mm}$ depth of de-ionized water. All the molten pools are wide and shallow which indicates a large focal spot size due to the scattering of light and refraction by water. Figure 3 shows typical SEM micrographs of CGI melted by laser under different depths of de-ionized water. As can be seen in the figure, the modified CGI consists of typical ledeburite structures, i.e. dendritic cementite networks and austenitic dendrites. Austenitic dendrites are characterized by main arms and secondary arms, as shown in figure 3. As the water film thickness increases, spacing of these main dendrites decreases, which indicates a higher cooling rate during solidification. The high cooling rate causes the liquid of the original austenite to crystallize as primary dendrites. The last liquid will be enriched in carbon and form a eutectic of austenite and cementite. The eutectic was a divorce type because the eutectic austenite formed on the primary austenite leaving cementite surrounding the austenite dendrites.

It has been confirmed that the microstructure of CGI processed by laser immersed into water is much more refined in comparison with that processed in air [26]. Figure 4 presents 

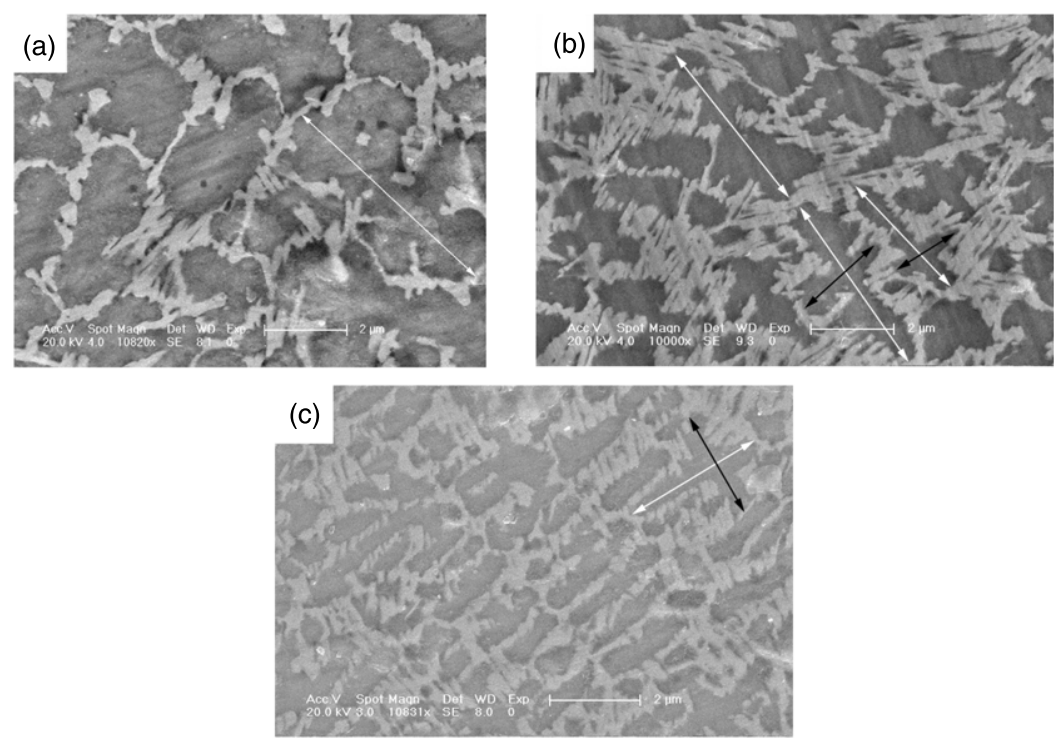

Figure 3. EFESEM photographs of the surface of CGI melted in water film, where white arrows represent main arms and black arrows represent second arms: (a) $1 \mathrm{~mm},(b) 2 \mathrm{~mm}$ and (c) $3 \mathrm{~mm}$.
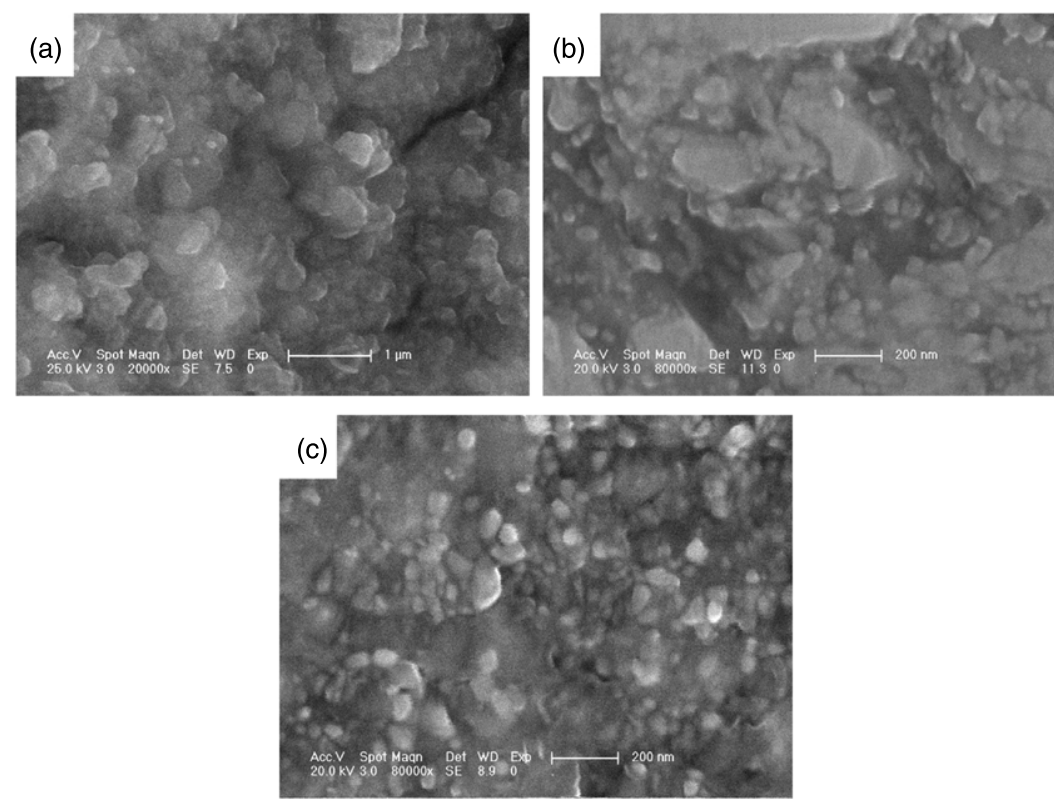

Figure 4. EFESEM photographs of the surface of GCr15 melted in water film: (a) $1 \mathrm{~mm},(b) 2 \mathrm{~mm}$ and (c) $3 \mathrm{~mm}$.

typical SEM images of GCr15 melted under different depths of de-ionized water. Apparently, fine equiaxed crystalline microstructure is produced during laser irradiation under water. The generated nano-sized grains exhibit a nearly spherical shape and can be regarded as ellipsoids, as shown in figures $4(b)$ and $(c)$. Figure 5 shows the SEM images of H13 melted under different depths of water. The size and shape distributions of $\mathrm{H} 13$ melted in de-ionized water also follow the same trend as that of $\mathrm{GCr} 15$. It is noticeable that a reduction in the mean size of the produced nano-sized grains is accompanied by an increase in the depth of de-ionized water. Although most of the nano-sized grains are relatively small as illustrated in figures $4(c)$ and $(c)$, a small amount of grains are much bigger, with a diameter around $200-250 \mathrm{~nm}$ (figures $4(b)$ and $5(b)$ ).
There is an inherent tendency that relatively small nanosized grains are produced by the LSM of the GCr15 and the H13 specimens, in comparison with the entirely different morpholoigies and grain sizes of crystals of CGI treated under the same experimental conditions. With the depth of de-ionized water increasing, the cooling rate is accelerated and the grain size is decreased gradually, as shown in figures 4 and 5. In fact, under a similar experimental condition, large grains on both of GCr15 and H13 are formed under the depth of $1 \mathrm{~mm}$, and the average diameter decreases greatly up to $50 \mathrm{~nm}$ with the depth increasing to $3 \mathrm{~mm}$. The diameter of grains differs due to inherent characteristics of materials as described above. It can be noted that the higher the cooling rate or the undercooling degree is, the higher the nucleation rate of austenite is. Therefore, the nucleation becomes highly 

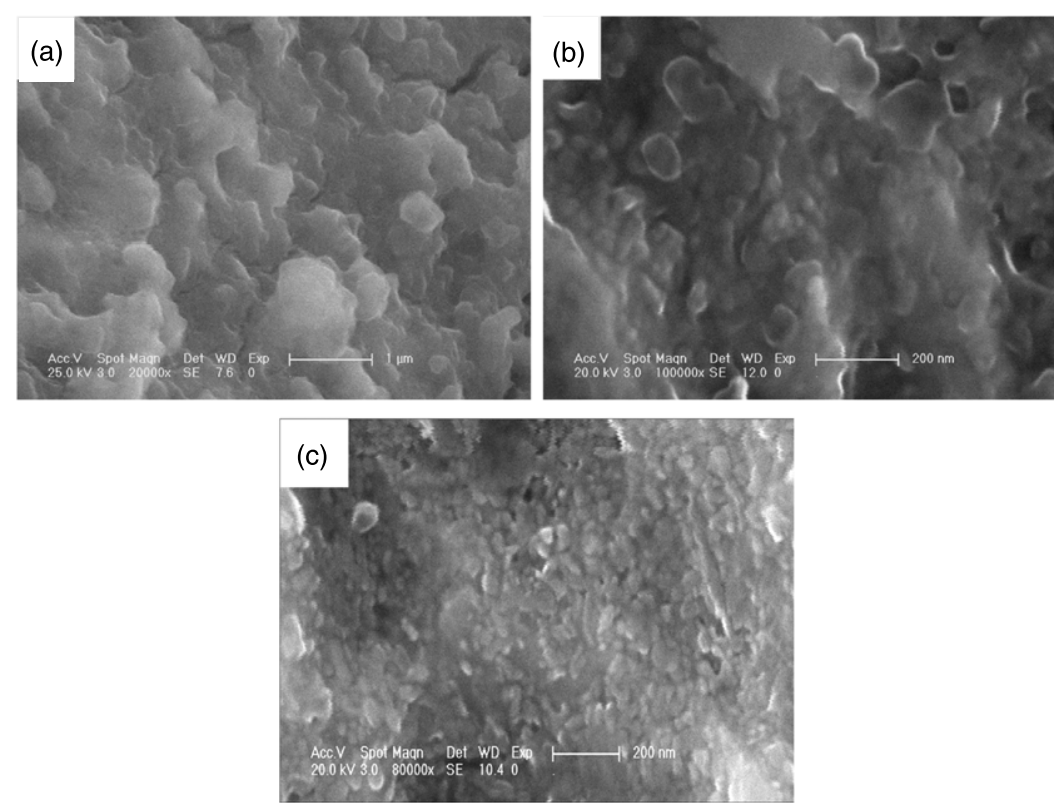

Figure 5. EFESEM photographs of the surface of H13 melted in water film: (a) $1 \mathrm{~mm},(b) 2 \mathrm{~mm}$ and (c) $3 \mathrm{~mm}$.

activated and finally leads to a decrease in the grain size. As a result, some austenite can be formed in nano-scale as the very large undercooling levels are achieved.

3.1.2. XRD characterization. Figure 6 shows XRD patterns of CGI, GCr15 and H13 specimens processed under different depths of de-ionized water. We have calculated the grain sizes $(D)$ in the melted zones using the Debye-Scherrer formula [27],

$$
\frac{\mathrm{FW}(s) \cdot \cos (\theta)}{\lambda}=\frac{K}{D}+4 \cdot \varepsilon \cdot \frac{\sin \theta}{\lambda},
$$

where $\lambda$ is the wavelength of the $\mathrm{x}$-ray source, $\mathrm{FW}(s)$ is the full width at half maximum (FWHM) of an individual peak at $2 \theta$ (where $\theta$ is the Bragg angle) and $\varepsilon$ is the lattice strain. The calculated grain size in the melted zone of the $\mathrm{GCr} 15$ specimens is $51.6008 \mathrm{~nm}$ and the strain is -0.07 . The result of XRD analysis confirms that there are austenite nanosized grains in the modified surfaces of GCr15. The SEM observation (figures 4 and 5) and TEM images (figure 7) demonstrate the presence of the nano-grains as well.

The diffractogram of the treated CGI samples (figure $6(a)$ ) shows high diffraction intensity at (1 010$),\left(\begin{array}{lll}1 & 1 & 0\end{array}\right),\left(\begin{array}{lll}2 & 0 & 0\end{array}\right)$ and (2 11 1) planes of martensite phase and (1 111$),\left(\begin{array}{lll}2 & 0 & 0\end{array}\right)$ and (2 20$)$ of residual austenite together with graphite, $\mathrm{Fe}_{3} \mathrm{C}$ and $\alpha$-ferrite. The diffractogram of melted GCr15 samples in figure $6(b)$ shows four strong diffraction peaks corresponding to the strong (1 010$),\left(\begin{array}{lll}1 & 1 & 0\end{array}\right),\left(\begin{array}{lll}2 & 0 & 0\end{array}\right)$ and $\left(\begin{array}{lll}2 & 1 & 1\end{array}\right)$ reflections of martensite. This diffractogram contains the (1 1 1), (200) and (220) peaks of residual austenite and the (1 1 0), (200) and (211) peaks of $\alpha$-ferrite. For the melted H13 specimens, the diffractogram (figure 6(c)) contains the strong (101), (1 1 10), (200) and

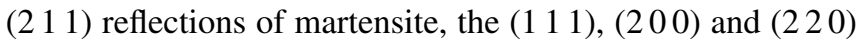
peaks of residual austenite and the (1 10$),\left(\begin{array}{lll}2 & 0 & 0\end{array}\right)$ and $(211)$ peaks of $\alpha$-ferrite. The XRD results indicate the phase changes of three kinds of material after laser melting treatment under water. In the present investigation, the martensite (2 111 ) peak looks compressed (figure 6(c)), which can be explained as follows. Here, segregation of chromium concentration plays a key role during martensitic transformation. The high chemical segregation of chromium concentration dissolving in the austenite $(5.36 \%)$ led to depression of the $M_{\mathrm{s}}$ and $M_{\mathrm{f}}$ temperatures leading to a high proportion of retained austenite at room temperature. Besides, it could be due to the insufficient time for carbon diffusion to occur due to supercooling during the martensitic transformation. Usually, LSM in air has been generally used to dissolve the precipitates like $\mathrm{M}_{23} \mathrm{C}_{6}$ at grain boundaries of austenite stainless steel. But no $\mathrm{M}_{23} \mathrm{C}_{6}$ carbides peaks are detected in our experiments. This can be interpreted as follows. The incident laser power reaching substrate surface is given by equation (2) [28]:

$$
T(z)=1-\mathrm{e}^{-\alpha \mathrm{z}},
$$

where $T(z)$ is the absorption at water depth (\%), $a$ is the absorptivity of water to laser beam $\left(0.014 \mathrm{~mm}^{-1}\right)$ and $z$ is the water depth $(\mathrm{mm})$. It was reported that the absorptivity of $1.06 \mu \mathrm{m}$ wavelength light by water is $0.014 \mathrm{~mm}^{-1}$ [29]. From equation (2) the theoretical laser power intensity reaching the specimen surface is about $93 \%$ of the incident laser when the water depth is $5 \mathrm{~mm}$. As the light beam is incident into water, some of the beam is reflected and some is refracted, with the refracted ray lying in the plane of incidence. It is confirmed that LSM cannot be performed if the water depth is more than $3 \mathrm{~mm}$ and laser energy density reaching the surface of specimens was low. According to the estimation of the cooling rates obtained during LSM as proposed by Steen [30], the lower the incident laser power, the lager the cooling rate. There would be the insufficient time to homogenize sensitized microstructure by dissolving $\mathrm{M}_{23} \mathrm{C}_{6}$ carbides [31]. 

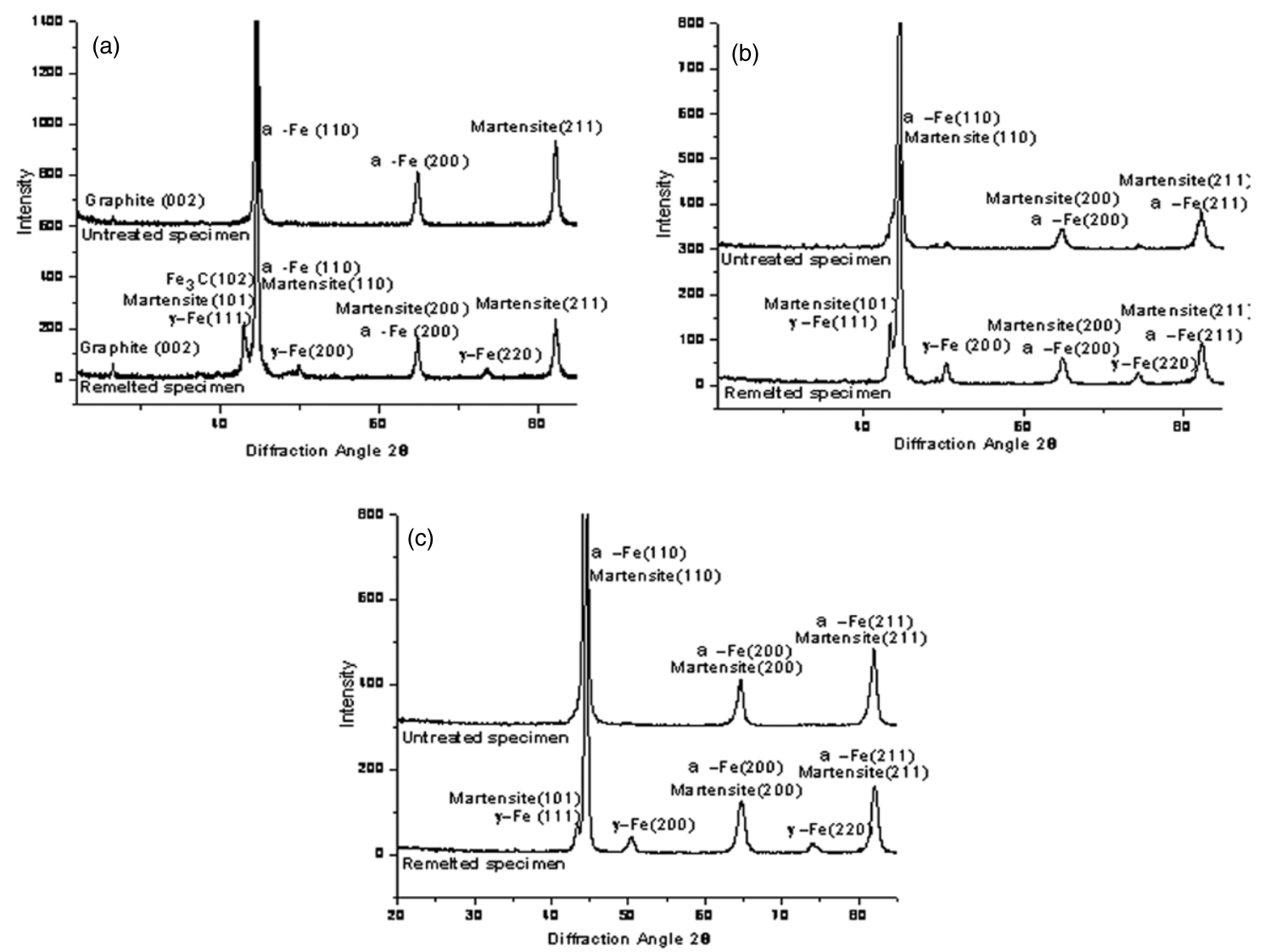

Figure 6. (a) Room temperature XRD pattern of the CGI: as-received substrate (upper curve) and the standard diffraction pattern of the specimen melted in water film of thickness $3 \mathrm{~mm}$ (lower curve); (b) room temperature XRD pattern of the GCr15: as-received substrate (upper curve) and the standard diffraction pattern of the specimen melted in water film of thickness $3 \mathrm{~mm}$ (lower curve); (c) room temperature XRD pattern of the H13: as-received substrate (upper curve) and the standard diffraction pattern of the specimen melted in water film of thickness $3 \mathrm{~mm}$ (lower curve).
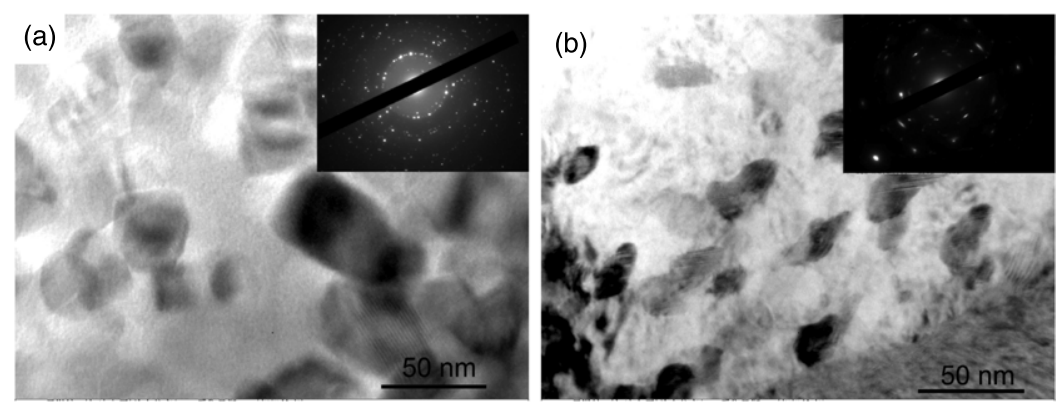

Figure 7. TEM images of the melted zone: (a) GCr15 melted in water in thickness of $3 \mathrm{~mm},(b) \mathrm{H} 13$ melted in water in thickness of $3 \mathrm{~mm}$.

\subsubsection{Morphology and structure characterization: TEM} and EDX. Figure 7 shows the HRTEM images of the microstructure at the melted zones of three kinds of material after processed by laser with a water film depth of $3 \mathrm{~mm}$. Figure 7(a) shows the agglomeration and clustering of nanosized grains in the matrix of GCr15 with a wide grain size range $6.73-60.22 \mathrm{~nm}$. The shape of the nano-sized grains is polyhedral-like. The Inset is the ring-like selected area electron diffraction (SAED) pattern, indicating that the microstructure consists of austenite (( 1111$),\left(\begin{array}{lll}2 & 0 & 0\end{array}\right)$ and (2 200$)$ ) and ferrite $\left(\left(\begin{array}{lll}1 & 1 & 0\end{array}\right)\right.$ and $\left.\left(\begin{array}{lll}2 & 1 & 1\end{array}\right)\right)$. From figure $7(b)$, the nanosized grains are uniformly distributed in the matrix of $\mathrm{H} 13$, as irregular shapes with a mean size of $37.49 \mathrm{~nm}$ in length. No obvious aggregations are observed in the as-prepared sample. According to the SAED pattern analysis, the microstructure consists of austenite and ferrite as well. The intermittent spots in the diffraction pattern verify the presence of $\gamma$-Fe as shown in figure 7. A typical EDX analysis (figure 8) is obtained from the electron beam being focused onto a single dark spot on the substrate. Figure $8(a)$ is a higher magnification image of the melted zone of GCr15 after laser melting process under a water film depth of $1 \mathrm{~mm}$. The composition of this spot is $1.43 \% \mathrm{Cr}$, $1.48 \% \mathrm{C}$ and $97.10 \% \mathrm{Fe}$, which is different from that of the base material. Figure $8(b)$ is collected at the melted zone of $\mathrm{H} 13$ 

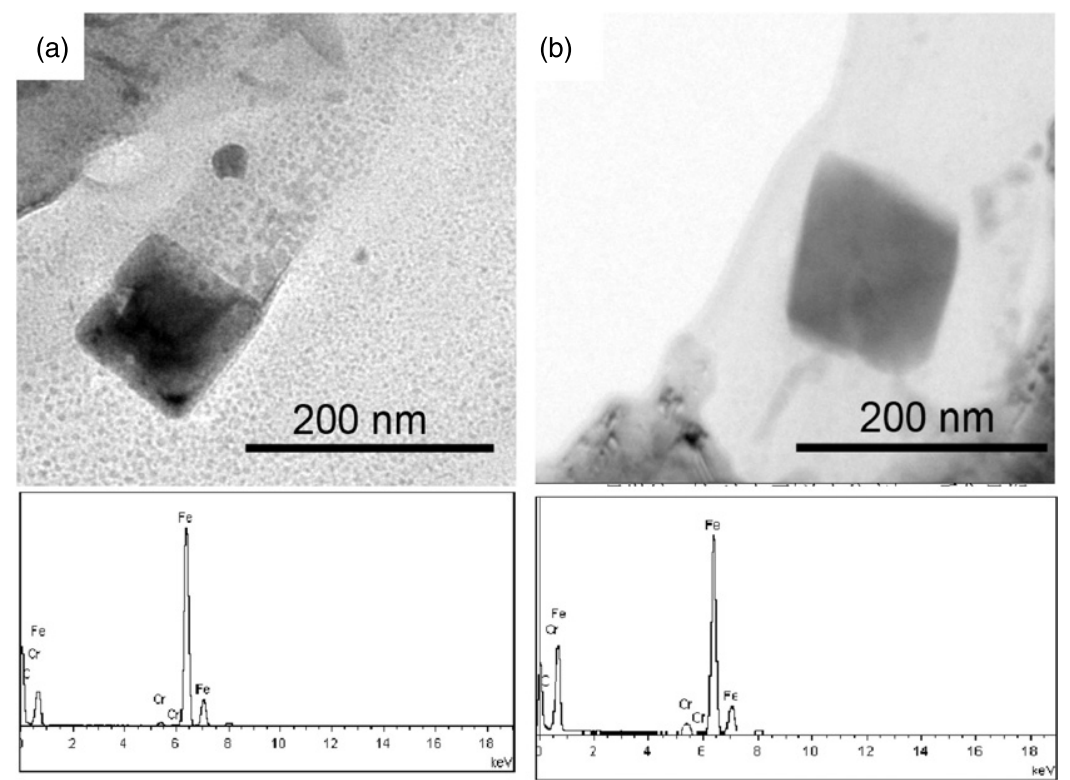

Figure 8. EDX analysis from a single dark spot: $(a) \mathrm{GCr} 15$ melted in water in thickness of $1 \mathrm{~mm},(b) \mathrm{H} 13$ melted in water in thickness of $1 \mathrm{~mm}$.

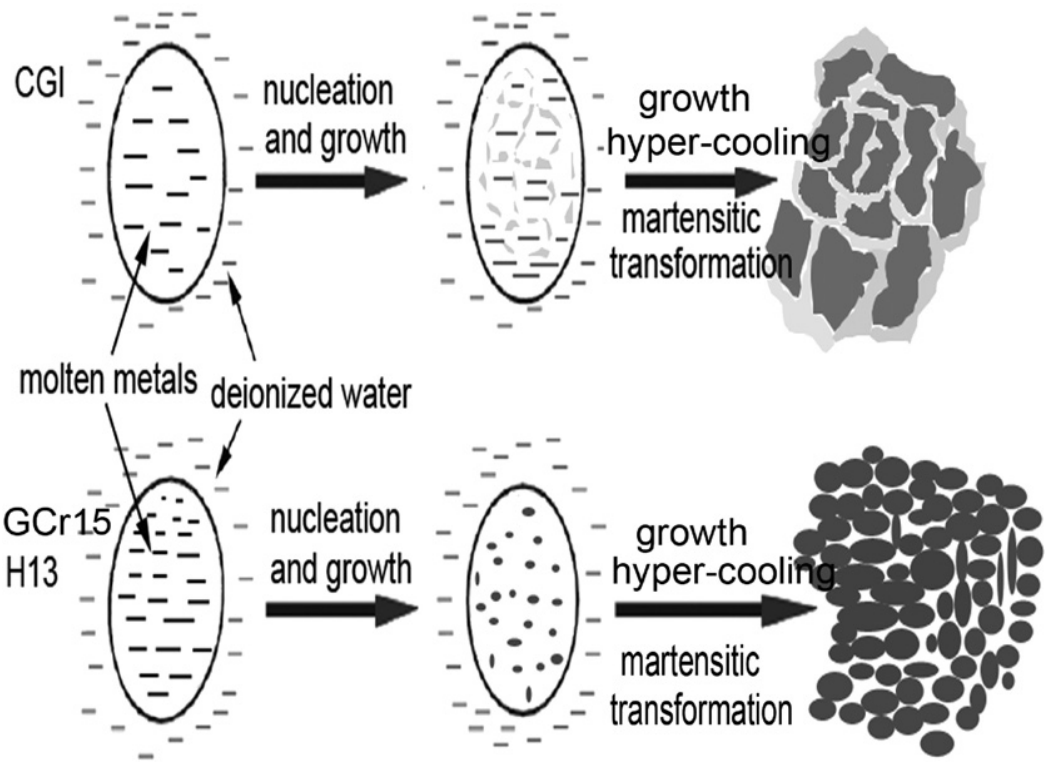

Figure 9. Illustration of the formation process of different microstructures.

processed with a water film depth of $1 \mathrm{~mm}$. As can be seen in figure $8(b)$, the composition of the particle contains $5.36 \% \mathrm{Cr}$, while that of the $\mathrm{H} 13$ base material is $5.12 \%$. Traces of carbon and iron in the spectra may originate in the particle itself or in remnants of steel attached to the crystals, due to chemical segregation during solidification.

\subsection{Metallurgy mechanism of different metal specimens}

Figure 9 illustrates the microstructure formation of different materials. In the case of the CGI $\left(T_{\mathrm{m}}: 1160^{\circ} \mathrm{C}\right)$, when the laser beam with high irradiance is rapidly scanned over the specimens, a liquid layer is produced. The high energy density of the laser leads to localized surface melting with efficient use of the energy. Although in water, some amount of laser energy is lost by absorption and reflection, almost all the energy is used for the melting of materials. The metallic liquid from the region of irradiation is cooled by flowing water and a large amount of heat is taken away by the water evaporation. Meanwhile, the specimens maintain a cold substrate that leads to very rapid quenching of the molten material after the short irradiation. Since the melting occurs only on the surface over a relatively short duration and the bulk of the substrate remains cool, the liquid metal in the molten pool will solidify and crystallize at an extremely high rate. At the beginning of solidification, the primary austenite forms and then crystallizes into the dendritic structure [32-37] perpendicularly to the solid-liquid interface. The growth occurs in a reverse direction of the heat transfer [26]. The remaining liquid will be enriched in carbon and cementite forms surrounding the austenite dendrites. When 
the temperature reaches the eutectic point, the eutectic reaction occurs. During the rapid solidification, most of the primary austenite and eutectic austenite could transform to the structure of martensite with some residual austenite. As a result, the final solidification structure of the melted zone is fine-grained martensite, cementite (the dendrite structure) and residual austenite.

The metallurgy of $\operatorname{GCr} 15\left(T_{\mathrm{m}}: 1460^{\circ} \mathrm{C}\right)$ and $\mathrm{H} 13\left(T_{\mathrm{m}}\right.$ : $1480^{\circ} \mathrm{C}$ ) is completely different from that of the CGI. The Gaussian energy distribution provokes a higher temperature on the surface of the two steels mentioned above. The surfaces are melted at a rapid heating rate due to the irradiation of laser. Afterwards, liquid metal in the molten pool solidifies and crystallizes at a high cooling rate, due to the water film. At the beginning of solidification, droplets from the melting pool are solidified in water and the primary austenite forms and then crystallize. The last liquid will be enriched in carbon and form carbides surrounding the austenite dendrites in the fusion zone. When the temperature reaches the eutectoid point, the eutectoid reaction occurs. The solidification structures are the primary austenite and carbides. Some of the austenite will transform to martensite due to the high temperature gradient applied locally on a small volume at the surface of the substrate.

\subsection{Formation mechanism of nano-sized grains}

The cooling rate in the liquid state is very high due to the water cooling, and $\mathrm{Cr}$ becomes enriched in the remaining liquid regions. Therefore, heterogeneous nucleation sites are dispersed due to the chemical segregation of chromium from the liquid. The rate of heterogeneous nucleation is deduced as follows. The activation energy for nucleation, $\Delta G^{*}$, is expressed as equation (3).

$$
\Delta G^{*}=\frac{4 \pi}{3} \frac{\sigma_{\mathrm{al}}^{3}}{\Delta G_{\mathrm{v}}^{2}}(2-\cos \theta)\left(1-\cos ^{2} \theta\right)^{2},
$$

where $\sigma_{\mathrm{al}}, \Delta G_{\mathrm{v}}$ and $\theta$ indicate the crystal-liquid interface energy, the volume free energy of crystallization and the wetting angle of the nucleus on the substrate, respectively. Based on the conclusions of Spaepen, Rieker and Morris [38-40], the interface energy is expressed as equation (4):

$$
\sigma_{\mathrm{al}}=\frac{0.86 \Delta H \cdot T}{T_{\mathrm{m}} N^{1 / 3} V^{2 / 3}},
$$

where $T$ is the temperature and $T_{\mathrm{m}}$ is the melting point. $\Delta H$ is the enthalpy of crystallization, $N$ is Avogadro's number and $V$ is the molar volume. The volume free energy of crystallization is calculated using the Dubey-Ramachandrarao approximation (equation (5)) [41].

$$
\Delta G_{\mathrm{v}}=\frac{\Delta H \cdot \Delta T}{T_{\mathrm{m}}}-\frac{\Delta C_{p} \Delta T^{2}}{2 T}\left(1-\frac{\Delta T}{6 T}\right),
$$

where $\Delta T$ is the undercooling and $\Delta C_{p}$ the difference in specific heats of the liquid and the solid. Based on the StokesEinstein equation and the Fulcher-Vogel expression [42, 43], the rate of heterogeneous nucleation is deduced in equation (6):

$$
I=\frac{k N_{\mathrm{s}} T}{3 \pi A a^{3}} \exp \left(-\frac{\Delta G^{*}}{R T}-\frac{B}{T-T_{\mathrm{g}}}\right),
$$

where $N_{\mathrm{s}}$ is the number of surface sites where heterogeneous nucleation may occur and $a$ is the interatomic distance. The constants $A$ and $B$ in this expression are deduced by making the viscosity at the melting point equal to $10^{-2} \mathrm{~N}_{s m}^{-2}$, using the activation energy for diffusion in the liquid at the melting point [44] and defining the glass temperature, $T_{\mathrm{g}}$. Thus, under the higher nucleation rate, nucleation centres having a very high density $\left(\sim 10^{19} \mathrm{~m}^{-3}\right)$ [40] can be activated, and the growth of the nucleation centres will be considerably suppressed under such conditions, leading to the creation of nano-sized grains. In addition, the melting point also has significant influence on cooling rate. The melting points of the three materials are obviously different, which indicates different undercooling degrees and the higher the melting point is, the higher the cooling rate is. According to some literature, the cooling rate for laser processed metal was reported to be up to $10^{13} \mathrm{~K} \mathrm{~s}^{-1}$ [45]. Such a high cooling rate would lead to the formation of the nano-sized grains at the surface of steel, by laser processing in water. The higher the chromium content is, the more nucleation sites exists, and the finer the nano-sized grains are, as shown in figure $7(b)$. Furthermore, the cooling effect of the water film on molten material should hinder the growth of the austenite structures generated in the molten zone. In other words, austenite phases can be frozen at the nano-scale in the final products during martensitic transformation due to the short cooling time (quenching time) in water.

\section{Conclusions}

LSM generates local liquid metal at the surface of specimen, which results in the formation of the cellular austenite structure during solidification, and simultaneous under cooling by a water film can lead to the formation of nano-sized grains in the form of rotational ellipsoids. Large grains are formed on the surfaces of GCr15 and H13 specimens by laser melting treatment under water with a $1 \mathrm{~mm}$ thickness of water film, and the average diameter decreases greatly to $50 \mathrm{~nm}$ when a $3 \mathrm{~mm}$ thickness of water film is employed. An increase in the thickness of water film is accompanied by a reduction in the mean size of the produced nano-sized grains. However, LSM of CGI specimens cannot produce austenite nano-sized grains under the same conditions. During solidification of CGr15 and H13, austenite precipitates as a cellular structure, which is much different from the dendrite structures in CGI. The laser melted surface layers have not the columnar grain structure typical of epitaxial regrowth, but a fine, equiaxed grain structure. It is concluded that the chemical segregation of chromium and the growth mechanism of austenite in liquid metal play a key role in the formation of nano-sized structures under a very large degree of supercooling.

The main advantage of the laser melting process under water is the ability to prepare uniform nano-sized grains without any pre- or post-treatments. This technique could lead to the formation of nano-grains with proper experimental parameters. Moreover, compared with other chemical or physical methods, this technique has the following advantages: simple procedures, controllable parameters, composition purity and no requirement for extreme temperature, pressure or 
a high vacuum system. This method could be extended to other metals, and these results have the basic and important meanings for further understanding the growth of nano-materials.

\section{Acknowledgments}

The authors would like to acknowledge the financial support by the Project 985-Automotive Engineering of Jilin University, the National Natural Science Fund of China (No 50635030) and the Science and Development Foundation of Jilin (No 20060196).

\section{References}

[1] Kannatey-Asibu E 2009 Principles of Laser Materials Processing (Hoboken, NJ: Wiley)

[2] Walker A, Flower H M and West D R F 1985 J. Mater. Sci. 20 989-95

[3] Riabkina-Fishman M and Zahavi J 1990 Mater. Manuf. Process. 5 641-60

[4] Tomlinson W J and Talks M G 1989 Wear 129 215-22

[5] Blarasin A, Corcoruto S, Belmonde A and Bacci D 1983 Wear 86 315-25

[6] Singh H B, Copley S M and Bass M 1981 Metall. Trans. A 12 138-40

[7] Niu H J and Chang I T H 2000 J. Mater. Sci. 35 31-38

[8] Su W N, Erasenthiran P and Dickens P M 2003 Proc. Inst. Mech. Eng. Part C J. Mech. Eng. Sci. 217 127-38

[9] Chiang K A and Chen Y C 2005 Mater. Lett. 59 1919-23

[10] Khan T I, Rizvi S A and Matsuura K 2000 Wear 244 154-64

[11] McDaniels R L, White S A, Liaw K, Chen L, McCay M H and Liaw P K 2008 Mater. Sci. Eng. A 485 500-7

[12] G Abbas, Li L, Ghazanfar U and Liu Z 2006 Wear 260 175-80

[13] Basu A, Chakraborty J, Shariff S M, Padmanabham G, Joshi S V, Sundararajan G, Dutta Majumdar J and Manna I 2007 Scr. Mater. 56887

[14] Khanna A S, Gasser A, Wissenbach K, Li M, Desai V H and Quadakkers W J 1995 J. Mater. Sci. 304684

[15] Heitkemper M, Bohne C, Pyzalla A and Fischer A 2003 Int. J. Fatigue 25101

[16] Garcia I and de Damborenea J 1998 Corros. Sci. 401411

[17] Fastow M, Bamberger M, Nir N and Landkof M 1990 Mater. Sci. Technol. 6900
[18] Pantelis D I, Bouyiouri E, Kouloumbi N, Vassiliou P and Koutsomichalis A 2002 Surf. Coat. Technol. 298125

[19] Kwok C T, Lo K H, Cheng F T and Man H C 2003 Surf. Coat. Technol. 166 221-30

[20] Conde A, Colaco R, Vilar R and de Damborenea J 2000 Mater. Des. 21 441-45

[21] Cui B, Wu L and Chou S Y 2008 Nanotechnology 19345303

[22] Xia Q F and Chou S Y 2009 Nanotechnology 20285310

[23] Youngdahl C J, Sanders P G, Eastman J A and Weertman J R 1997 Scr. Mater. 37 809-13

[24] Sanders P G, Eastman J A and Weertman J R 1997 Acta Mater. 454019

[25] Nieman G W, Weertman J R and Siegel R W 1991 J. Mater. Res. 6 1012-27

[26] Zhou H, Sun N, Shan H Y, Ma D Y, Tong X and Ren L Q 2007 Appl. Surf. Sci. 253 9513-20

[27] Cullity B D 1978 Elements of X-ray Diffraction 2nd edn (Reading, MA: Addison-Wesley)

[28] Zhang X D, Chen W Z, Ashida E and Matsuda F 2004 Opt. Laser. Eng. 41 717-30

[29] Takahashi K, Kobayashi H and Yoneyama T 2000 Preprints of the National Meeting of JWS (Japan Welding Society) vol 66, pp 70-1

[30] Steen WM 1991 Laser Material Processing (Berlin: Springer)

[31] Parvathavarthini N, Subbarao R V, Kumar S, Dayal R K and Khatak H S 2001 J. Mater. Eng. Perform. 10 5-13

[32] Rappaz M, David S A, Vitek J M and Boatner L A 1989 Metall. Trans. A 201125

[33] Kurz W and Trivedi R 1992 Trans. ASME 114450

[34] Kar A and Mazumder J 1987 J. Appl. Phys. 612645

[35] Guo W and Kar A 1998 Acta Mater. 46 3485-90

[36] Benyounis K Y, Fakron O M A, Abboud J H, Olabi A G and Hashmi M J S 2005 J. Mater. Process. Technol. $170127-32$

[37] Juarez-Islas J A 1991 J. Mater. Sci 26 5004-12

[38] Spaepen F 1975 Acta Metall. 23729

[39] Spaepen F and Meyer R B 1976 Scr. Metall. 10257

[40] Rieker C and Morris D G 1990 Acta Metal. Mater. 38 1037-43

[41] Dubey K S and Ramachandrarao P 1984 Acta Metall. 3291

[42] Kelly T F and VanderSande J B 1987 lnt. J. Rapid Solidif. 351

[43] Davies H A 1976 J. Phys. Chem. Glasses 17159

[44] Brandes E A and Smithells C J (ed) 1983 Metals Reference Book (London: Butterworths)

[45] Wang G X and Prasad V 2000 Mater. Sci. Eng. A 292142 